\title{
Tumor necrosis factor- $\alpha$ (TNF- $\alpha$ ) in glutathione (GSH)-depleted rats. A possible link to impaired glucose metabolism
}

\author{
Sohair A. Moustafa \\ Department of Zoology, Faculty of Science, Suez Canal University, Ismailia, Egypt.
}

\begin{abstract}
Rats: treated with the glutathione depleting agent, allyl alcohol (AlAl) $(1 \mathrm{mmol} / \mathrm{kg})$ was found to induce a marked increase in serum TNF- $\alpha 45$ minutes post treatment. This increase is suggested to play a critical role in the development of impaired glucose metabolism and glucose intolerance in AlAl-treated rats. Impaired glucose metabolism was evidenced by the significant increase in serum creatinine, urea and blood urea nitrogen accounting for accelerated glycolysis and breakdown of creatinine phosphate. These are the metabolic consequences of the activation of a back up system for the generation of ATP when the primary energy forming pathway is impaired. Meanwhile, the present data show a significant decrease in the serum levels of triglycerides and cholesterol in AlAl-treated rats that was accompanied with a concomitant increase in their liver levels indicating the development of fatty livers in these rats. Due to the strong link between TNF- $\alpha$ and the GSH status and to the well established role of TNF- $\alpha$ in causing insulin resistance, which is potentiated by fat accumulation in different tissues, it is concluded that the combination of TNF- $\alpha$ overproduction, GSH depletion and lipid accumulation in the liver caused by $\mathrm{AlAl}$ treatment, cooperate making cells more sensitive to AlAl poisoning, therefore, imposing a potent negative impact on glucose metabolism. Added to the deleterious effects of TNF- $\alpha$, enhanced lipid peroxidation observed in AlAl- treated rats suggests possible alterations in the rates of glucose transport and metabolism which may further contribute to $\mathrm{AlAl}$-induced impairment in glucose metabolism.
\end{abstract}

Conclusion: Finally, the selective effect of TNF- $\alpha$ in inhibiting insulin secretion give an additional support to its hypothesized role in initiating glucose intolerance in GSH-depleted rats.

Key words : TNF- $\alpha$, rats, glutathione depletion, glucose metabolism impaired glucose metabolism

\section{Introduction}

Over the past decade, there has been substantial interest in oxidative stress and its potential role in diabetogenesis, development of diabetic complications and atherosclerosis (Evans et al., 2003). Oxidative stress develops when free radical generation exceeds the body's antioxidant production capacity (Roth, 2000). Tumor necrosis factor (TNF- $\alpha$ ) is an inflammatory cytokine that causes cell injury by generation of oxidative stress (Adamson and Billings, 1992 \& Goosens et al,. 1995). Moreover, TNF- $\alpha$ has emerged as a key player in the progression of insulin resistance seen in obesity and obesitylinked type 2 diabetes (Ruan et al,. 2002). However, the mechanistic link between TNF- $\alpha$ and insulin resistance remain unclear.
Since glutathione (GSH) is the major redox buffer of several eukaryotic cell types that detoxifies reactive oxygen species, it is hypothesized that persistent TNF- $\alpha$ secretion could induce oxidative stress through modulation of glutathione (GSH) metabolism. Actually several studies have addressed this hypothesis (FernandezCheca et al. , 1987 and Higuchi et al. 1996, Adamson and Billings, 1992 and Glosli et al., 2002). Moreover, GSH has been found to exert a protective function against the cytocidal effect of TNF by inhibiting the hydroxyl radical production stimulated by TNF (Yamauchi et al., 1990).

Allyl alcohol (AlAl) is one of the hepatotoxins that readily conjugate with hepatic glutathione to produce extensive GSH depletion followed by cellular 
damage; therefore expected to induce deleterious effects to several biological systems. GSH depletion has previously been reported to induce impaired glucose metabolism in the rat. However, the involvement of TNF- $\alpha$ in this impairment has not been revealed. The current study was designed to provide further insights into roles of GSH depletion, TNF- $\alpha$, and glucose metabolism in AlAl-treated rats.

\section{Material and Methods}

Male Wistar rats were housed three per cage and allowed free access to standard chow and water except in those experiments utilizing fasted rats, where food was withheld for $24 \mathrm{hr}$. Ally alcohol (AlAl) dissolved in saline $(10 \% \mathrm{v} / \mathrm{v})$, was given intraperitoneally at the dose of 1 $\mathrm{mmol} / \mathrm{kg}$ (Maellaro et al., 1990). Blood samples were withdrawn 45 minutes posttreatment for the determination of different serum parameters. Control rats were given an equivalent volume of saline.

\section{Determination of serum metabolite}

Serum samples were used for the determination of blood glucose, urea, blood urea nitrogen (BUN) and creatinine. Serum samples for lactate and pyruvate determination were analyzed in the National Research Center (Cairo, Egypt) using Sigma reagents (St Louis, Mo, USA).

\section{Estimation of glutathione and lipid peroxidation}

Rats were sacrificed 45 minutes following $\mathrm{AlAl}$ treatment. Livers were quickly excised, dry blotted and weighed. Liver glutathione was estimated according to the method of Tieze (1969). Liver lipid peroxidation was measured by the thiobarbituric acid (TBA) test as described by Uchiyama and Mihara (1978).

\section{Glucose tolerance test (GTT)}

$$
\text { Intra-peritoneal (i.p) glucose }
$$

tolerance test (GTT) was performed $45 \mathrm{hr}$ after $\mathrm{AlAl}$ treatment. Glucose load $(3 \mathrm{~g} / \mathrm{kg})$ was given to 24 hours-fasted rats, blood samples were obtained from lightly anesthetized rats with ether from the orbital sinus at $0,30,60$, and 120 minutes post glucose loading.

\section{Statistical analysis}

The data were analyzed using one way ANOVA (King and Minium, 3003)

\section{Results}

Oxidative stress and inflammatory response induced by AlAl treatment

GSH depletion in the liver and pancreas (indicative of oxidative stress) was seen in AlAl-treated rats as compared to control rats $(\mathrm{P}=0.051 ; 0.015$ for liver and pancreas respectively). Oxidative stress was further assessed with TBA levels which were elevated in the livers of AlAl-treated rats relative to control rats $(\mathrm{P}=0.038)$ (table 2).

The inflammatory response induced by $\mathrm{AlAl}$ treatment was evidenced by the elevated levels of serum TNF- $\alpha$ in AlAltreated rats compared to control rats $(\mathrm{P}=$ 0.023) (table 2)

\section{Impaired glucose metabolism in AIAI- treated rats}

Impaired glucose metabolism in AlAltreated rats was indicated by the increase in the serum levels of creatinine, urea and blood urea nitrogen (BUN) reflecting impaired primary energy forming pathway and accelerating glycolysis and the breakdown of creatinine phosphate for the generation of ATP. Statistically significant increases of urea and BUN were observed $(\mathrm{P}=0.024 ; \quad 0.047$ for urea and $\mathrm{BUN}$ respectively) (table 3 ).

\section{Effect of AlAl treatment on serum and liver lipids}

Serum triglycerides and cholesterol levels were significantly decreased in AlAltreated rats compared to control rats $(\mathrm{P}=$ 0.00014 and 0.024 for triglycerides and cholesterol respectively). These values were accompanied with a concomitant increase in their hepatic levels $(\mathrm{P}=0.028$ and 0.053 for triglycerides and cholesterol respectively) probably reflecting the development of fatty livers in AlAl-treated rats (table 3) .

\section{Liver damage caused by AlAl treatment}

Liver damage was evident by the elevated levels of serum GPT in AlAl group compared to control group $(\mathrm{P}=0.012)$ (table 3). 
Table 1: Intra-peritoneal (i.p) glucose tolerance test (GGT) in control and AlAl-treated rats.

\begin{tabular}{|c|c|c|}
\hline & Control & $\mathrm{AlAl}$ \\
\cline { 2 - 3 } 0 time & $104.00 \pm 4.23$ & $123.33 \pm 1.20^{*}$ \\
30 minutes & $310.45 \pm 82.08$ & $471.72 \pm 31.02^{*}$ \\
60 minutes & $321.67 \pm 86.07$ & \\
120 minutes & $401.32 \pm 66.87$ & $466.93 \pm 36.23$ \\
\hline
\end{tabular}

Treated rats were injected with $\mathrm{AlAl}(1 \mathrm{mmol} / \mathrm{kg})$ (i.p). I.P. glucose tolerance test (GTT) was performed $45 \mathrm{hr}$ after AlAl treatment. Glucose load ( $3 \mathrm{~g} / \mathrm{kg}$ ) was given to 24 hoursfasted rats, blood samples were obtained at $0,30,60$, and 120 minutes post glucose loading. Values were represented as mean \pm .S.E. of five rats.

$* \mathrm{P} \leq 0.05$ control versus treated.

Table 2: Oxidative stress parameters in control and AlAl-treated rats.

\begin{tabular}{|l|c|c|}
\hline & Control & AlAl \\
\cline { 2 - 3 } & $222.43 \pm 21.92$ & $335.36 \pm 35.45^{*}$ \\
TNF- $\alpha(\mathrm{ng} / \mathrm{ml})$ & & \\
& & $16.83 \pm 3.74^{*}$ \\
GSH $(\mathrm{mg} / \mathrm{g})$ & $26.85 \pm 2.01$ & $13.66 \pm 0.89^{*}$ \\
Liver & $20.01 \pm 1.25$ & $0.146 \pm 0.03^{*}$ \\
pancreas & $0.073 \pm 0.01$ & \\
TBA & & \\
\hline
\end{tabular}

Treated rats were injected with $\mathrm{AlAl}(1 \mathrm{mmol} / \mathrm{kg}$ ) (i.p). Rats were sacrificed 45 minute post treatment. Values were represented as mean \pm .S.E. of five rats.

$* \mathrm{P} \leq 0.05$ control versus treated. 
Table 3: Levels of serum and liver metabolites in control and AlAl-treated rats.

\begin{tabular}{|l|c|c|}
\hline & Control & AlAl \\
\hline GPT (U/L) & $43.3 \pm 2.44$ & $59.47 \pm 2.74^{*}$ \\
Creatinine (mg/dl) & $0.63 \pm 0.033$ & $0.73 \pm 0.033$ \\
& $22.45 \pm 1.02$ & $28.93 \pm 1.97^{*}$ \\
Urea (mg/dl) & $11.25 \pm 0.478$ & $14.67 \pm 1.33^{*}$ \\
BUN (mg/dl) & & \\
Triglycerides & $86.6 \pm 2.91$ & $31.65 \pm 3.90^{*}$ \\
Serum (mg/dl) & $114 \pm 8.13$ & $139.23 \pm 5.53^{*}$ \\
Liver (mg/g) & & \\
& & \\
Cholesterol & $62.57 \pm 1.58$ & $49.97 \pm 3.18^{*}$ \\
Serum (mg/dl) & $2.70 \pm 0.37$ & $3.90 \pm 0.21^{*}$ \\
Liver (mg/g) & & \\
\hline
\end{tabular}

Treated rats were injected with $\mathrm{AlAl}(1 \mathrm{mmol} / \mathrm{kg})$ (i.p). Rats were sacrificed 45 minute post treatment. Values were represented as mean \pm .S.E. of five rats.

$* \mathrm{P} \leq 0.05$ control versus treated.

\section{Discussion}

In an extension for a prior study (Moustafa, 1998) examining the impact of GSH depletion (due to AlAl treatment) on glucose metabolism, the current study was undertaken to reveal the possible implication of the inflammatory cytokine TNF- $\alpha$ in impaired glucose metabolism in rats treated with AlAl. Results of the present study extend and support previous findings of Moustafa (1998) showing glucose intolerance and impaired glucose metabolism in GSH depleted (AlAltreated) rats. The significant increase in serum creatinine, urea and BUN accounting for accelerated glycolysis and breakdown of creatinine phosphate which are the metabolic consequences of the activation of a back up system for the generation of ATP when the primary energy forming pathway is impaired (Lehnenger, 1970). Actually, the study of Adamson and Billings (1992) indicated that TNF- $\alpha$ caused a marked decrease in cellular ATP concentrations, which occurred secondary to effects on the glutathione pool. Thus, the elevated TNF- $\alpha$ levels observed in AlAl-treated rats may contribute at least in part to impaired glucose metabolism and energy deprivation observed in these rats.

In addition to this apparent impairment in glucose metabolism, the significant decrease in serum triglycerides and cholesterol that were accompanied with a concomitant increase in their hepatic levels may reflect the development of fatty livers in AlAl-treated rats. The inhibition of outward triglyceride and cholesterol transport could be the mechanism initiating this effect. Inhibited lipoprotein synthesis by the endoplasmic reticulum was suggested to be the source of the development of fatty livers in carbon tetrachloride $\left(\mathrm{CCl}_{4}\right)$-treated rats, since lipoproteins are involved in the transport of lipids from the liver (Poli et al., 1985).

The etiology of impaired glucose metabolism in AlAl-treated rats seems to be multifactorial. TNF- $\alpha$ is known to cause 
cell injury by generation of oxidative stress (Morales et al., 1997), meanwhile oxidative stress is documented to be a major contrib.utor to insulin resistance in diabetes (Evans et al., 2003) and aging (Campisi, 2001). In mice, chronic exposure of cells or whole animals to TNF- $\alpha$ induces insulin resistance, and treatment with soluble forms of TNF- $\alpha$ receptors neutralize this effect (Uysal et al., 1997). Furthermore, mice with targeted gene deletion of TNF- $\alpha$ or its receptors showed increased insulin sensitivity and improved plasma FFA levels (Uysal et al., 1997). Additionally, resistin and TNF- $\alpha$ have been shown to directly impair insulin signalling and consequently, insulin stimulated glucose uptake in muscle (Dyck et al., 2006). Moreover, exposure of adipocytes to TNF- $\alpha$ has been found to result in reduced protein levels of GLUT4 and several insulin signaling proteins, including the insulin receptor, insulin receptor substrate 1 (IRS-1), and protein kinase B (AKT) (Ruan et al,. 2002). It is worthy to refer to the study of Moustafa et al. (1995) showing impaired glucose transport in adipocytes of aged rats. Oxidative stress and enhanced lipid peroxidation in these cells were suggested to mediate this impairment. It would, therefore, seem logical to suggest that AlAl-induced oxidative stress may result in alteration in the rate of glucose transport and/or one of the more distal intracellular processes affecting glucose metabolism. The defect in glucose transport is of special significance since glucose transport is the rate limiting step for overall glucose metabolism (Fink, 1986).Therefore, its inhibition must result in the total decrease of glucose uptake leading to increased resistance.

There are several lines of evidence to support the hypothesis that a strong link exists between TNF- $\alpha$ and the GSH status which should impose a strong impact on glucose metabolism. It has been reported that persistent TNF- $\alpha$ secretion could induce oxidative stress through modulation of glutathione (GSH) metabolism (Glosli et $a l .$, 2002). Using transgenic mice, it has been found that oxidative stress induced by persistent low-grade exposure to TNF- $\alpha$ caused marked organ-specific alterations in GSH redox status and GSH-regulating enzymes, with the most pronounced changes in the liver (Glosli et al., 2002). In addition, hepatocytes exposed to recombinant human TNF- $\alpha$ were found to exhibit intracellular GSH depletion and GSSG efflux (Adamson and Billings, 1992). On the other hand, GSH depletion was found to enhance the inflammatory response to various stimuli (e.g., TNF- $\alpha$ ) leading to further enhancement of oxidative stress, potentially constituting a vicious circle causing augmented tissue injury (Glosli et al., 2002). Moreover, repletion of GSH in the liver mitochondria in acute alcoholic hepatitis, restores normalized TNF- $\alpha$ - induced mitochondrial dysfunction and cytotoxicity (Fernandez-Checa et al., 1987 and Higuchi et al., 1996). Finally, irreversible inhibition by L-buthionine$(\mathrm{S}, \mathrm{R})$-sulfoximine (BSO) of gammaglutamylcysteine synthetase, the ratelimiting enzyme in the biosynthesis of glutathione (GSH), induces intracellular accumulation of ROS and augments release of interleukin (IL)-1beta, IL-6, and tumor necrosis factor alpha (TNF- $\alpha$ ) (Haddad, 2000).

Thus, it can be concluded that augmented oxidative stress caused by GSH depletion and TNF- $\alpha$ overproduction could initiate a broad spectrum of impaired cell signaling pathways including insulin signaling, apparently, this effect may account for impaired glucose metabolism and glucose intolerance in AlAl-treated rats.

It is worthy to mention that there is considerable focus on the view that lipid accumulation in skeletal muscle and liver leads to the development of insulin resistance. In experimental models, enhanced cholesterol levels due to alcohol consumption and subsequent deposition into liver mitochondria was found to induce selective decrease in the mitochondrial GSH stores which was sufficient by itself to sensitize hepatocytes to TNF- $\alpha$ mediated cell death (Fernandez-Checa, 2003). Therefore, it seems almost to be an obvious deduction that the combination of TNF- $\alpha$ overproduction, GSH depletion and lipid accumulation in the liver caused by AlAl treatment cooperate making cells more sensitive to AlAl poisoning. Obviously, it can be hypothesized that fat accumulation in the livers of AlAl-treated rats (table 3) 
may reflect a TNF- $\alpha$ mediated mechanism contributing to insulin resistance and glucose intolerance in these rats.

Based on previous data showing that TNF- $\alpha$ causes a selective inhibition of insulin release in rat islets without causing cell death (Rabinovich et al. 1992), it is suggested that impaired insulin release due to AlAl treatment could be a contributing factor to AlAl-induced glucose intolerance, and that overproduced TNF- $\alpha$ mediates this effect. Impaired insulin release in response to glucose challenge in AlAl-treated rats, previously reported by Moustafa (1998) clearly supports this view. Actually, pancreatic B-cells islets are known to be highly vulnerable to oxidative stress damage due to their low antioxidant potential (Lenzen et al,. 1996), making them highly susceptible to ROS- mediated cyto destructive effects of TNF- $\alpha$. Interestingly, is the hypothesis that TNF$\alpha$ and GSH depletion could exert cytocidal effects through differential mechanisms. It has been found that dose-dependent necrosis was the exclusive mode of cell death with the GSH depleting agent acetaminophene (APAP) alone, but the addition of TNF-- $\alpha$ induced a switch to about half apoptosis without changing total loss of viability. Thus, in addition to ROSmediated cyto-destructive effects of TNF- $\alpha$ on pancreatic islets, this differential effect may explain the effect of TNF- $\alpha$ in inhibiting insulin release without causing cell death which was suggested to be a functional not a destructive effect and may not be ROS-mediated (Rabinovich et al., 1996).

\section{References}

1. Adamson G, and Billings RE (1992): Tumor necrosis factor induced oxidative stress in isolated mouse hepatocytes. Arch. Biochem. Biophys., 294(1): 223-229.

2. Brown $L$ S, Frank $L$, Harris, $F$ L and Guidot, D.M. (2001): Chronic ethanol ingestion potentiates TNF- $\alpha$ mediated oxidative stress and apoptosis in rat type II cells. Am. J. Physiol. Lung. Cell. Mol. Physiol., 281: L377-L386.

3. Campisi J (2001): From cells to organisms: can we learn about aging from cells in culture? Exp. Gerontol., 36(4-6): 607-18.
4. Dyck D, Heigenhauser $\mathbf{G}$ and Bruce $\mathbf{C R}$ (2006): The role of adipokines as regulators of skeletal muscle fatty acid metabolism and insulin sensitivity. Acta. Physiol (Oxf)., 186(1): 5-16.

5. Evans JL, Goldfine ID, Mddux BA and Grodsky GM (2003): Are oxidative stress activated signaling pathways mediators of insulin resistance and $B$-cell dysfunction. Diabetes, 52: 1-8.

6. Fink RI, Huecksteadt $\mathbf{T}$ and Karaoghlanian $Z$ (1986): The effects of aging on glucose metabolism in adipocytes from Fischer rats. Endocrionology, 118: 1139-1147.

7. Fernandez-Checa JC, Ookhtens $M$ and Kaplowitz N (1987): Effect of chronic ethanol feeding on rat hepatocytic glutathione: compartmentation, efflux and response to incubation with ethanol. J Clin Invest., 80: 57-62.

8. Fernandez-Checa JC (2003): Alcoholinduced liver disease: when fat and oxidative stress meet. Ann. Hepatol., 2(2): 69-75.

9. Glosli H, Tronstad $\mathbf{K J}$, wergedal $\mathbf{H}$, Müller F, Svardal A, Aukrust P, Berge RK and Prydz H (2002): Human TNF- $\alpha$ in transgenic mice induces differential changes in redox status and glutathione-regulating enzymes. The FASEB Journal, 16:14501452.

10. Goosens V, Grooten, J, Vos Jde and Fiers W (1995): Direct evidence for tumor necrosis factor-induced mitochondrial reactive oxygen intermediates and their involvement in cytotoxicity. Proc. Natl. Acad. Sci. USA., 92: 8115-8119.

11. Gordon WM, Garcia JM, Konig A, Goldenthal M, Lu X and Feng Q (2004): In vivo TNF- $\alpha$ inhibition ameliorates cardiac mitochondrial dysfunction, oxidative stress, and apoptosis in experimental heart failure. Am. J. Physio.l Heart. Circ. Physiol., 287: H1813-H1820.

12. Haddad JJ (2000): Glutathione depletion is associated with augmenting a proinflammatory signal: evidence for an antioxidant/pro-oxidant mechanism regulating cytokines in the alveolar epithelium. Cytokines. Cell. Mol. Ther., 6(4): 177-187.

13. Higuchi H, Kurose I, Kato S, Miura S and Ishi H (1996): Ethanol-induced apoptosis and oxidative stress in hepatocytes. Alcohol. Clin. Exp. Res., 20: 340A-346A.

14. King BM and Minium EW (2003): Statistical Reasoning in Psychology and Education, Fourth Edition. Hoboken, New Jersey: John Wiley \& Sons, Inc. 
15. Lehnenger AL (1970): Contractile and motile systems. In: Bbiochemistry. Edited by Worth. Worth Publisher Inc. New York. N.Y. PP. 583-604.

16. Lenzen S, Drinkgern $J$ and Tiedge $M$ (1996): Low antioxidant enzyme gene expression in pancreatic islets compared with various other mouse tissues. Free Radic Biol Med., 20: 463-466.

17. Mellaro E, Casini AF Bello, BD and Comporti M (1990): Lipid peroxidation and antioxidant systems in liver injury produced by glutathione depleting agents. Biochem. Pharmacol., 39(10): 1513-1521.

18. Moe G, W Garcia J M, Konig A, Goldenthal M Lu X and Feng Q (2004): In vivo TNF- $\alpha$ inhibition ameliorates cardiac mitochondrial dysfunction, oxidative stress, and apoptosis in experimental heart failure. Am. J. Physiol. Heart. Circ. Physiol., 287: H1813-H1820.

19. Morales A, Garcia-Ruiz C, Miranda M, Mari M, Colell A, Ardite $\mathbf{E}$ and Fernandez-Checa JC (1997): Tumor necrosis factor increases hepatocellular glutathione by transcriptional regulation of the heavy subunit chain of gammaglutamylcysteine synthetase. J. Biol. Chem., 272(48): 30371-30379.

20. Moustafa SA (1998): Effect of glutathione depletion on carbohydrate metabolism in the rat. Res. Commun. Pathol. Toxicol., 3: 5564.

21. Moustafa SA, Webster JE, and Mattar FE (1995): Effects of aging and antioxidants on glucose transport in rat adipocytes. Gerontol., 41: 301-307.

22. Moustafa SA (2001): Effect of glutathione (GSH) depletion on the serum levels of triiodothyronine (T3), thyroxine (T4) and T3/T4 ratio. Possible protection with zinc. International Journal of Toxicology (USA), 20(1):15-20.

23. Poli G, Chiarpotto E, Albano E, Cattalasso D, Nanni G, Marinai UM, MBassi A and Dianzani MU (1985):
Carbon tetrachloride inhibition of hepatocyte lipoprotein secretion: functional impairment of Golgi apparatus in the early phases of such injury. Life sci., 36: 533-539.

24. Rabinovich A, Suarez WL, Thomas PD, StrynadkaK and Simson I (1992): Cytotoxic effects of cytokines on rat islets: Evidence for involvement of free radicals and lipid peroxidation. Diabetologia, 35: 409-413.

25. Rabinovich A, Suarez-Pinzon WL, Thomas PD, Strynadka K, Simson I, Lakey JRT and Rajotte RV (1996): Human pancreatic islet $\beta$-cell destruction by cytokines involves oxygen free radicals and aldhyde production. J. Clin. Endocrinl. Metab., 81: 3197-3202.

26. Ruan H, Hacohen N, Golub TR, Van Parijs L and Lodish HF (2002): Tumor necrosis factor-alpha suppresses adipocytespecific genes and activates expression of preadipocyte genes in 3T3-L1 adipocytes: nuclear factor-kappaB activation by TNFalpha is obligatory. Diabetes, 51(5):131936.

27. Tieze F (1969): Enzymic method for quantitative determination of nanogram amounts of total and oxidized glutathione. Applications to mammalian blood and other tissues. Anal. Biochem., 27: 502-522.

28. Uchiyama $M$ and Mihara $M$ (1978): Determination of malonaldehyde precursor in tissues by the thiobarbituric test. Anal. Biochem., 86: 271-278.

29. Uysal KT, Wiesbrock SM, Marino MW and Hotamisligil GS (1997): Protection from obesity-induced insulin resistance in mice lacking TNF- $\alpha$ function. Nature, 389: 610-614.

30. Yamauchi N, Watanabe $\mathbf{N}$, Kuriyama $\mathbf{H}$, Neda H, Maeda M, Himeno T, Tsuji Y, Niitsu Y (1990): Suppressive effects of intracellular glutathione on hydroxyl radical production induced by tumor necrosis factor. Int. J. Cancer, 46(5): 884-888. 


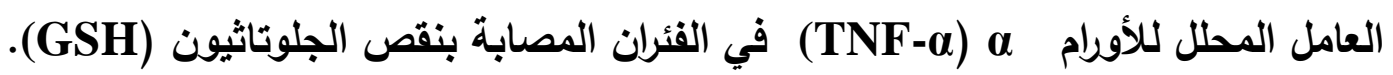
العلاقة المحتملة لإحداث الاختلال في تمثيل جزئ الجلوكوز

\author{
سهير عبد الله مصطفي \\ قسم علم الحيوان - كلية العلوم - جامعة قناة السويس - الإسماعيلية- مصر مصلئ
}

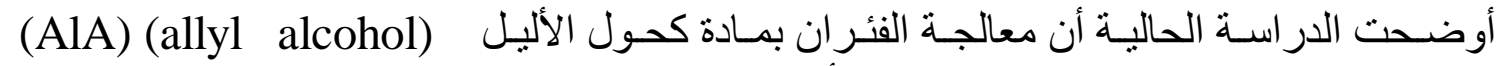

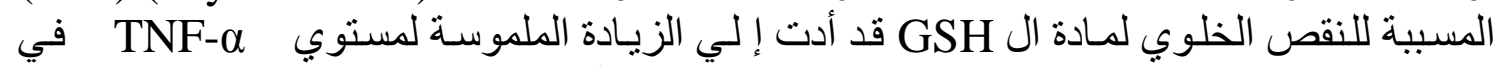

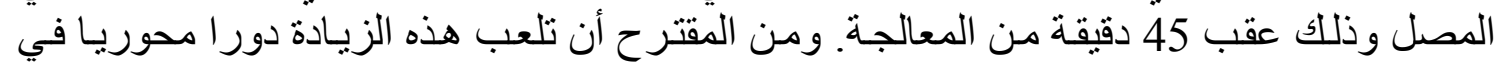

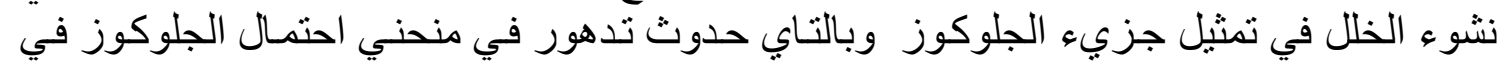

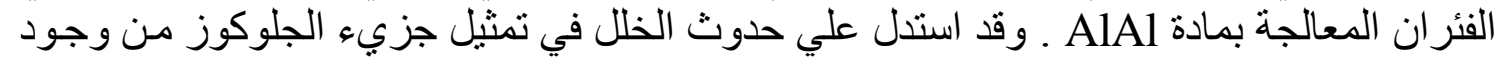

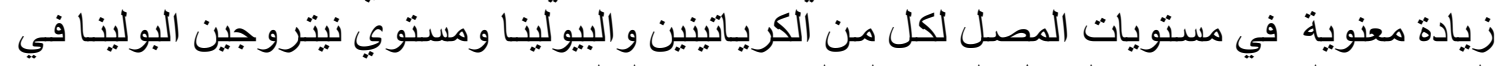

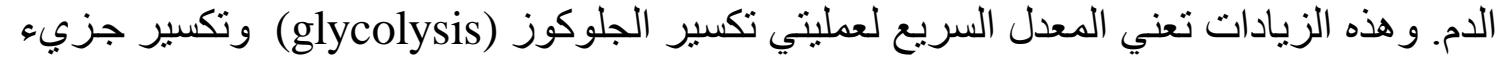

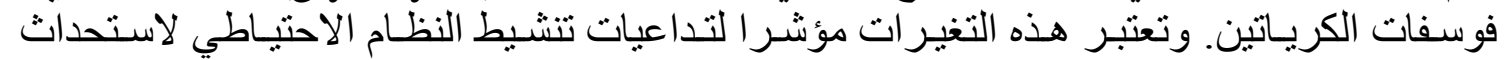

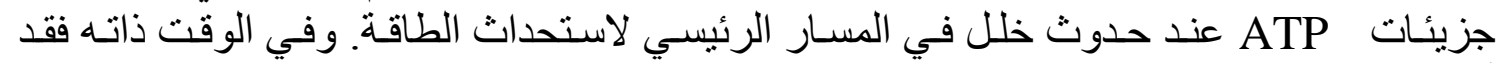

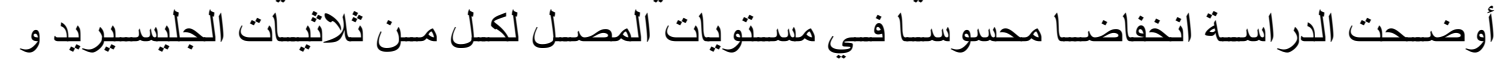

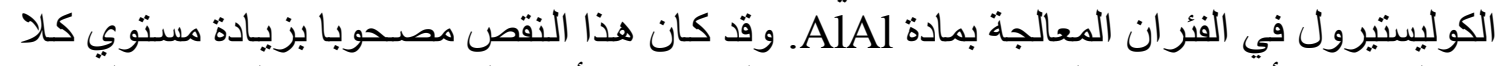

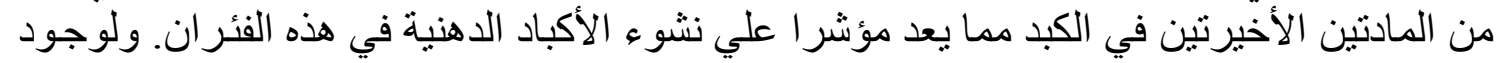

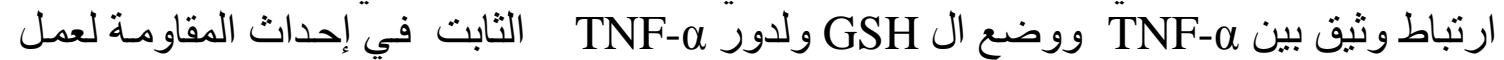

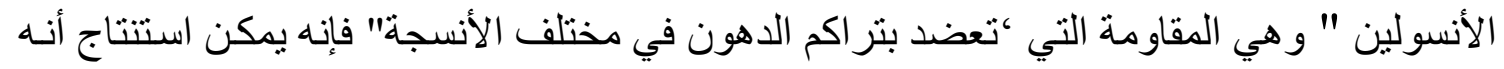

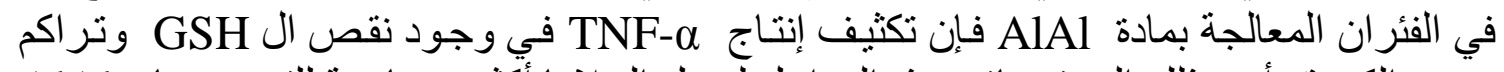

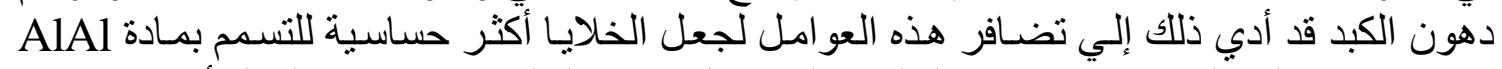

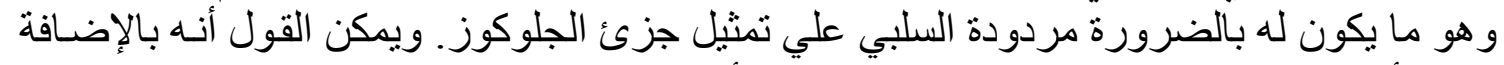

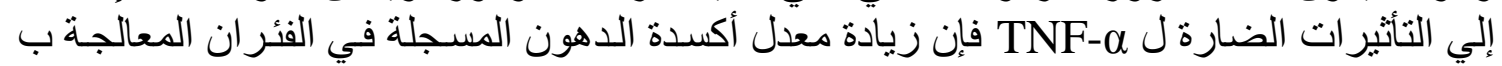

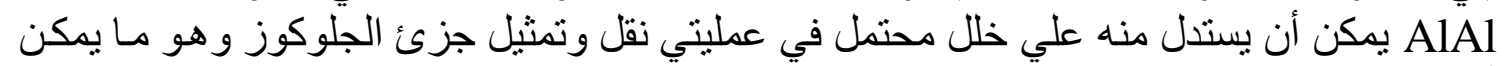

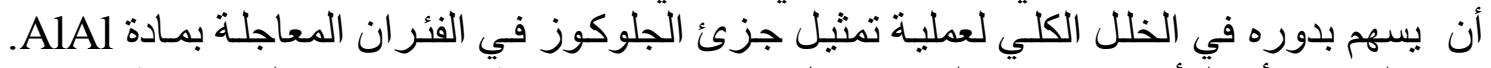

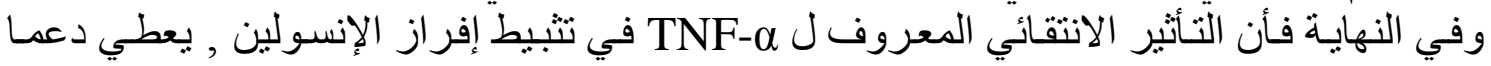

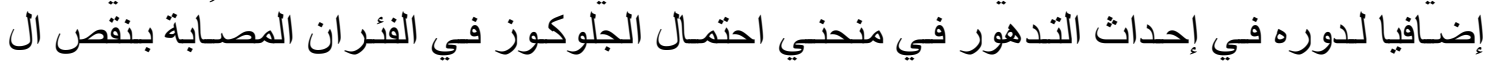

.GSH 